\title{
Rose diagrams and statistical tests for archaeological orientation data: a case applied to the Southfleet Road Elephant site, Ebbsfleet, UK
}

\author{
Richard J. Hewitt ${ }^{1}$, Simon A. Parfitt ${ }^{2}{ }^{3}$ and Francis F. Wenban-Smith ${ }^{4}$
}

\begin{abstract}
Archaeologists and other fieldworkers frequently record the orientation of artefacts or faunal remains in order to understand depositional and post-depositional processes. However, analysis of this kind of data is complex and not always well-understood by investigators. For example, rose diagrams are commonly used to display orientation data. While rose diagrams are a useful and intuitive way of visualizing the data, they are not on their own sufficient except in cases where preferential orientation is very evident. Class frequency, rather than the square root of class frequency, is commonly used to interpret the results. This can give a misleading impression of preferential orientation, when in fact observed patterns do not deviate significantly from random. Conversely, data may deviate significantly from random but this may not be clear from the diagram. At the same time, classic tests like the chi-square test are not appropriate for the display of circular data and alternative approaches are needed. This paper discusses the history of the use of rose diagrams to display orientation data, briefly reviews the archaeological literature in this regard, and discusses key problems and limitations. We then make some recommendations for best practice, which we demonstrate using R software for the Lower Palaeolithic "elephant butchery site" at Southfleet Road, Ebbsfleet, UK, excavated in 2004. The methods employed are clearly explained and all data are provided to ensure that the procedure is easily repeatable without specialist knowledge or programming experience.
\end{abstract}

Keywords: circular data; orientation patterns; rose diagrams; Rayleigh test, Kuiper test, R software

\footnotetext{
${ }^{1}$ Observatorio para una Cultura del Territorio, C/ Duque de Fernán Núñez, Madrid 28012, Spain

${ }^{2}$ Department of Earth Sciences, The Natural History Museum, Cromwell Rd, London SW7 5BD, United Kingdom

${ }^{3}$ University College London, Institute of Archaeology, 31-34 Gordon Square, London WC1H 0PY, United Kingdom

${ }^{4}$ Department of Archaeology, University of Southampton, Avenue Campus, Highfield, Southampton, SO17 1BF, United Kingdom
} 


\section{Introduction}

Fieldworkers in archaeology and related geographical or spatial sciences frequently record the orientation of artefacts, sediments or features as means of learning about their deposition or subsequent modification by natural or anthropogenic processes. For example, bones of mammals naturally collected by the action of water flowing along a stream bed would be preferentially aligned in the direction of water flow, resulting in preferred orientation of bone long-axes markedly different to an undisturbed scatter of bones from animal butchery by a hominid group (see, e.g. Voorhies 1969, Shipman and Rose 1983). Orientation is also relevant to more recent archaeological periods, since human cultures and societies have frequently tended to bury their dead aligned towards features or monuments such as mountains, astral bodies, or places of religious or cultural significance (Pearson 1999). Earth scientists also are frequently interested in orientation; sediment particles or drifting snow may be aligned in the direction of the prevailing wind, the orientation of stones (or linear scratches) in sediments or soils may signal the position of a downhill slope or the flow direction of a watercourse or sediment body (see e.g. Krumbein 1939, Rigsby 1960, Dietzel and Kleber 2012). And yet, while there are a number of excellent standard texts discussing the statistical treatment of so-called circular data (e.g. Fisher 1993, Jammalamadaka and Sengupta 2001), an up-to-date and detailed discussion of methods applicable to archaeological cases is generally lacking. In addition, while many, perhaps most, studies of orientation data in archaeology and related geographical sciences use a popular graphical technique known as a rose diagram to display and interpret the data, the technique has some pitfalls which are not commonly aired, and, we think, ought to be more widely known. Though several excellent alternative methods of displaying orientation data have been advanced in the literature (Wells 2000), rose diagrams are ideal for simplicity and clarity. However, a detailed discussion of how to use them appropriately in an archaeological context is long overdue. Finally, most studies of orientation go no further than the graphical depiction of the orientation measurements, complemented by an intuitive interpretation of significance or otherwise. Although a pattern may seem very clear from the diagram, the graphic is rarely accompanied by the necessary or suitable statistical testing

In this article we address some of these shortcomings and research gaps with application to a recent archaeological case study from the UK, where excavations in 2004 at Southfleet Road, Ebbsfleet, in advance of the High Speed 1 rail link revealed a fragmented specimen of the extinct straighttusked elephant Palaeoloxodon antiquus in sediments dating to the Middle Pleistocene, c. 420,000 
BP [years Before Present]. The skeletal remnants were associated with flint artefacts, and the site was interpreted as representing butchery of the carcass by a group of hominids (Wenban-Smith 2013). We begin by discussing the history of rose diagrams for displaying orientation data. We then briefly review the literature, discuss some of the difficulties of the technique and the data, leading us to make some recommendations for best practice. We then show the detailed application of the technique to the Southfleet Road elephant site data, and demonstrate the application of a pair of useful statistical tests that are robust and easy to apply.

\section{Research Background}

Orientation measurements were displayed in the form of rose diagrams, a form of representing circular or periodic data attributed to Florence Nightingale (see Fisher 1993), the nineteenth century medical reformer and founder of applied statistics. In Nightingale's work, the circular plot depicted months of the year, with class frequencies being the number of deaths recorded in the British army from various causes for each month of the year. Schmidt (1917), investigating the micro-crystalline structure of slate, analysed orientation data by dividing class frequencies into $5^{\circ}$ groups, and plotting them as points on a compass circle at a distance from the centre of the circle equal to the class frequency. By joining the points, orientation data were expressed as spikes extending outward from a circle, preferential orientation being highlighted by the zones having the longest distance from the centre of the circle. The key difference between Nightingale's rose and Schmidt's diagrams relates to Nightingale's use of a wedge, rather than a spike, and that Nightingale plotted the area of the wedge as proportional to the class frequencies, while Schmidt made a decision that has resurfaced in discussion of orientation rose diagrams ever since (see Wells 2000, and discussion later on in this section), and plotted the petal length as proportional to class frequency. Numerous examples of rose diagram plots are found in geological, palaeontological and archaeological literature and the most usual form is essentially a combination of Nightingale's area wedge approach and Schmidt's radius distance method $^{5}$; see, for example, Shipman (1981, also citing earlier material), Kreuzer (1987), Bertan and Texier (1995), Roberts et al (1997), Sahnouni and de Heinzelin (1998), McPherron (2005), Bernatchez (2010), and Allen et al (2015).

Wells (2000), who has investigated in some depth the use of rose diagrams and other types of plots for circular datasets, cautions that rose diagrams are not appropriate for all orientation data, since they are rather sensitive to (usually arbitrary) decisions about class width (bin size) and starting

5 Although see Dibble 1997 for an approach rather closer to Schmidt's original method. 
position, and care should be taken, for example, if evidence of preference for a particular degree class is sought, rather than a generalized preference for a cardinal direction ${ }^{6}$. Wells' principal concern, however, relates to the frequent use of Schmidt's, rather than Nightingale's, approach to radius wedge lengths, whereby rose petals are scaled proportionally to class frequency rather than area (see also Fisher 1993), as this exaggerates the size of the rose petals giving a misleading impression of the degree of variation between the classes. It might be argued that this is not an error as such, rather an exaggeration of tendencies in the data, but nevertheless, given the limitations mentioned above regarding class width and starting position, it should be avoided, so as not to give the misleading impression of preferential orientation (patterned data), where the distribution in fact differs little from that obtainable by chance. Fortunately, this problem can be easily avoided by ensuring that the radii of the wedges are equal to the square root, not the value of the relative class frequencies. Many rose diagram plotting packages (e.g. GeoOrient) already take this into account though some (e.g. Rosetta) do not. In this analysis, which we carried out in the R statistical environment, we used the CircStats package module rose.diag, which allows for square root scaling ${ }^{7}$.

Some types of data, such as bone long-axes in a palaeo-channel, may be considered to have one of two possible orientations, depending on the starting point chosen by the fieldworker to record the bearing; these types of data are typically plotted as what Shipman (1981) refers to as "mirrorimage" rose diagrams, that is, rose diagrams where one half of the compass circle reflects exactly the other; most of the archaeological and palaeolontological examples from the literature, e.g Kreuzer (1987), Roberts et al (1997), Sahnouni and de Heinzelin (1998) are of this type. The other type, which need not concern us here, are derived from measurements of vectors having a clear "direction from" and "direction to", such as wind data, or as in one recent study, of ice-rafted boulders whose location and "walk" orientation had been recorded year-on-year over several seasons (Allen et al 2015).

Statistical tests of significance for preferred orientations have, naturally enough, developed

\footnotetext{
6 Often, this may not present a problem. For example, in a recent paper on orientation data for ice-rafted boulders on the surface of Lake Hoare, Antarctica (Allen et al 2015), these considerations were found not to be relevant in the light of the clear grouping of orientations in the upper left hand section of the compass circle (preferential orientation toward the north-west).

$7 \quad$ Other rose diagram plotting modules are available $\mathrm{n} \mathrm{R}$, such as rose and rose 2 from the heR.Misc package. To our knowledge, neither of these modules offer an option available as is to draw petal radii according to the square root of class frequency.
} 
alongside graphical plotting techniques such as rose diagrams. It will suffice to say here that virtually any statistical treatment of circular data is subject to various caveats, but in general, the most commonly used significance test, the chi-square test, where sample class frequencies are tested against a theoretical probability curve derived from the chi-square distribution, is nowadays regarded by most authors as inadequate, following criticism of the technique by, amongst others, Ballantyne and Cornish (1978), and Wells (1990). The main problem seems to be that by simply varying the point of origin for the class groupings, a wide range of chi-square values are obtained, such that no one value can be considered to represent the sample set, and meaningful results are not therefore obtainable. Various alternative options have been explored, such as Ajne's $A_{n}$ statistic (Dale and Ballantyne 1980), comparison of sample data with idealized models (Shipman 1981), a modified chi-square test (Wells 1990), and the Rayleigh test (Bernatchez 2010).

\section{Case study: the Southfleet Road elephant site}

Ground works carried out in 2003 during the construction of the High Speed 1 rail link and Ebbsfleet International station (HS1) in the Ebbsfleet valley, northwest Kent (Figure 1) revealed a complex sequence of Pleistocene sediments . Controlled excavations carried out the following year revealed the remains of a partial skeleton of straight-tusked elephant Palaeoloxodon antiquus, in association with a dense cluster of mint condition lithic artefacts (Wenban-Smith 2013). Though subsequent detailed investigation of the elephant bones did not reveal any unequivocal evidence of cut marks relating to butchery, the condition of the associated flint artefacts indicates early human tool manufacture on the spot, strongly suggesting direct exploitation of the elephant carcass.

Excavations recovered 47 fragmentary identifiable elephant elements, two molars, two substantial portions of the left and right

tusks and 27 tusk fragments from an area of around $25 \mathrm{~m}^{2}$, with a separate scatter of articulating foot bones $c .15 \mathrm{~m}$ to the northeast. The lack of duplication in the bones and consistency in size and ontogenetic age indicate that all the bones came from a single, extremely large adult individual. The main scatter had a linear form, orientated approximately northwest to northeast. (Parfitt et al 2013). Given that the bones belonged to a single individual, and that some were articulated, investigators were keen to investigate their orientation in order to understand site formation processes, and to consider the possible role of human behaviour as opposed to natural processes. 


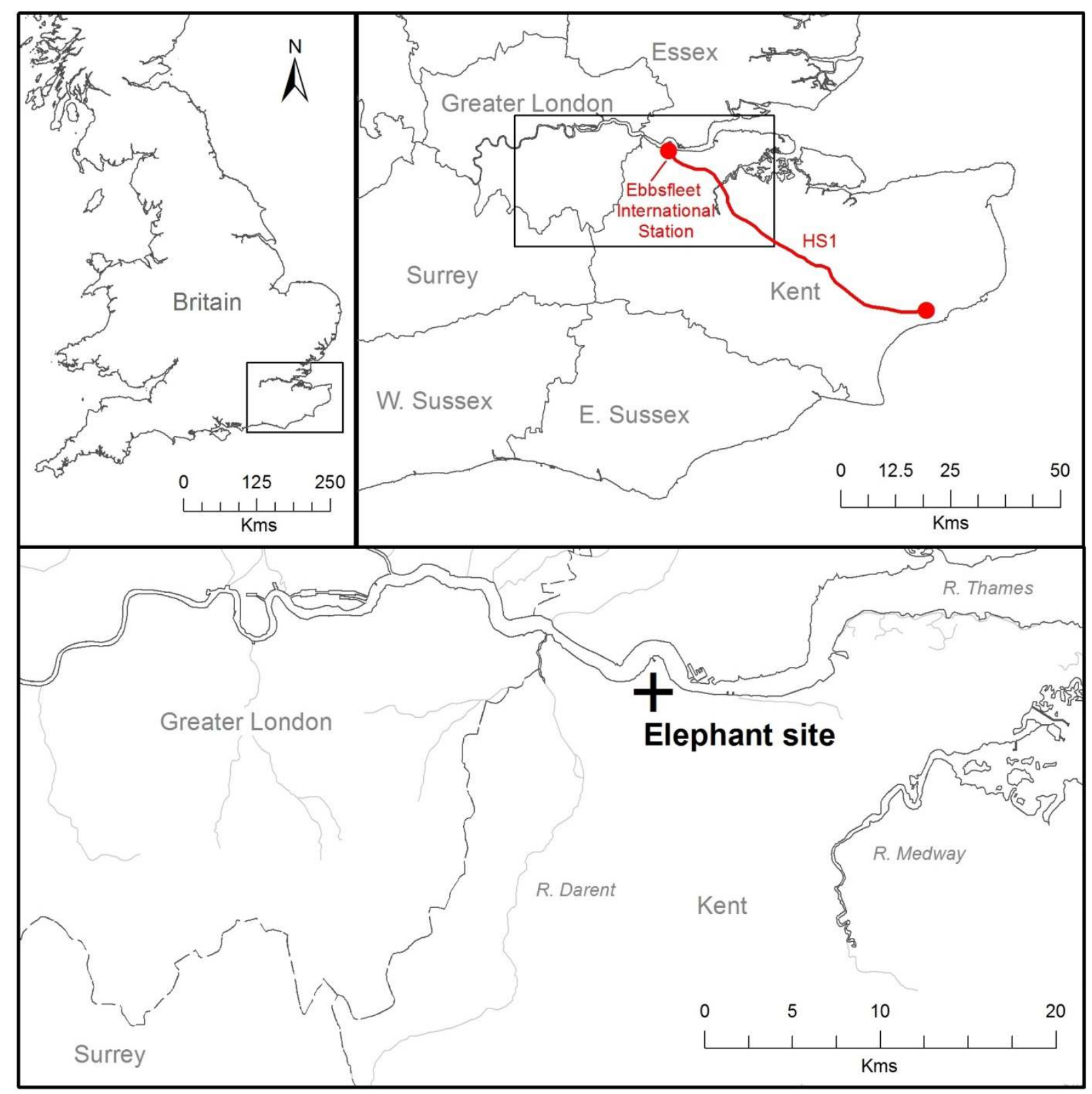

Figure 1: Location of the Southfleet Road elephant site, Ebbsfleet Valley, Kent

\section{Methods}

Bone long axes orientations were recorded by excavators in the field using a compass. Since a bone can be said to point in either of two directions separated by $180^{\circ}$, no preference was given in the field to either compass mode, thus $1^{\circ}$ and $181^{\circ}$ represent the same angle of orientation. The data were manually recorded, hand-entered into spreadsheet software, and imported into R software (R Core Team 2016) for analysis (Table 1). $\mathrm{R}$ was then used to plot the data, using the CircStats package module rose.diag (Lund and Agostinelli 2018). 
Table 1 (below). Data for orientation of elephant long bone fragments by 20 degree classes, showing class frequency. Data are axial, not vectorial (each measurement has two potential orientations separated by 180 degrees).

\begin{tabular}{lll} 
ID & class & frequency \\
\hline 1 & $0-20$ & 4 \\
2 & $21-40$ & 2 \\
3 & $41-60$ & 14 \\
4 & $61-80$ & 8 \\
5 & $81-100$ & 13 \\
6 & $101-120$ & 10 \\
7 & $121-140$ & 6 \\
8 & $141-160$ & 6 \\
9 & $161-180$ & 3 \\
\hline TOTAL & & 66
\end{tabular}

The full R-command line output for the dataset is given in Appendix I.

The aspace library was required to convert the data to radians, and the CircStats library was used to plot the rose diagrams with the rose.diag module. As the data are axial orientations (each measurement has two potential orientations separated by 180 degrees) the data were combined with their mirror image, to produce a mirror-image rose diagram of 132 orientations (Figure 2). This common technique for representing axial data is acceptable visually, but is not suitable for statistical analysis. The appropriate techniques for statistical analysis of axial data are discussed in the following section.

After generating the plot, graphics software was used to flip and rotate the diagram to follow the standard conventions for geographical coordinates (rose.diag by default outputs to mathematical coordinate conventions, where angles turn anti-clockwise from zero at the right hand side of the circle). Alternate bars were filled following Kreuzer (1987). Figure 1 shows the results of this plot. 
Figure 2: Mirror-image Rose Diagrams of elephant bone long-axis orientations from Southfleet Rd. Left hand plots in $10^{\circ}$ bins, right hand plots in $20^{\circ}$ bins. A \& B: raw plots from $\mathrm{R}$ with angles turning counter-clockwise from $0^{\circ}$ at the right; $\mathrm{C} \& \mathrm{D}$ : Rotated and flipped to turn angles clockwise from $0^{\circ}$ at the top of the plot; E \& F: Alternate bars filled for emphasis, after Kreuzer (1987).

A

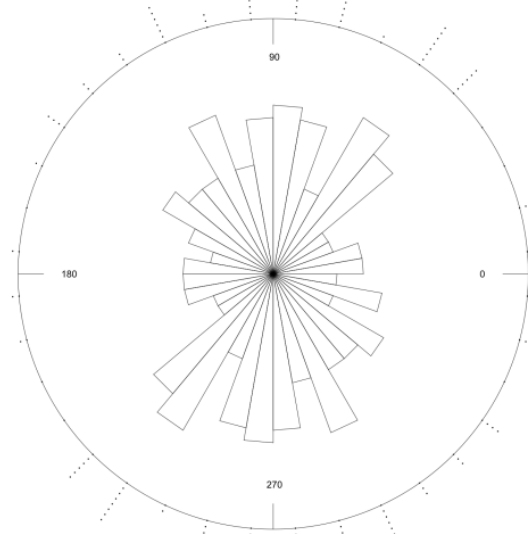

C

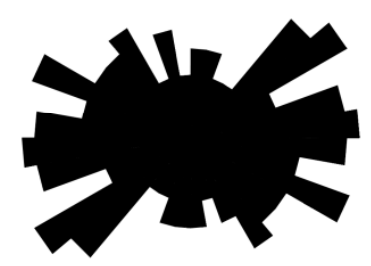

E

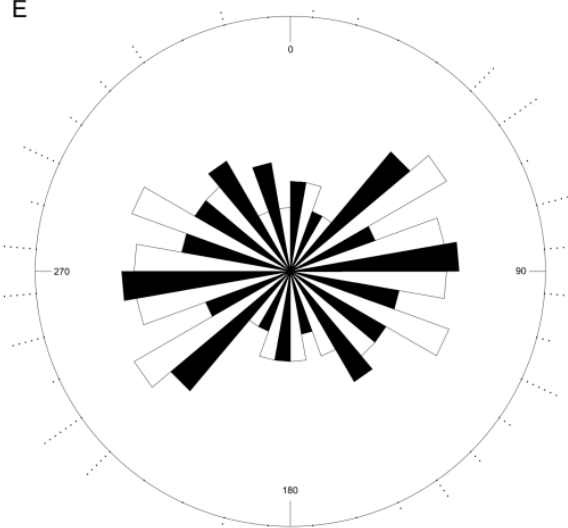

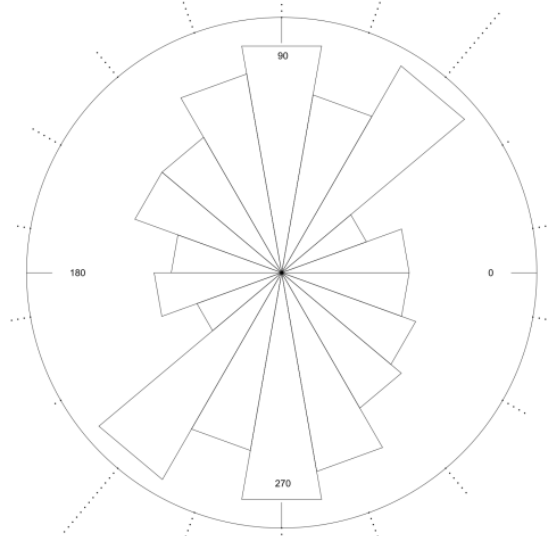

D

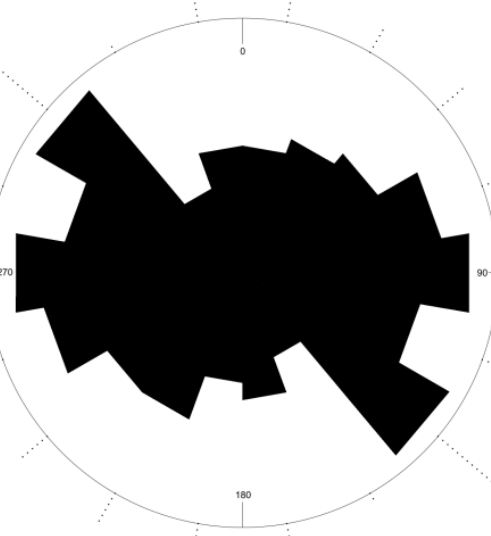

$\mathrm{F}$

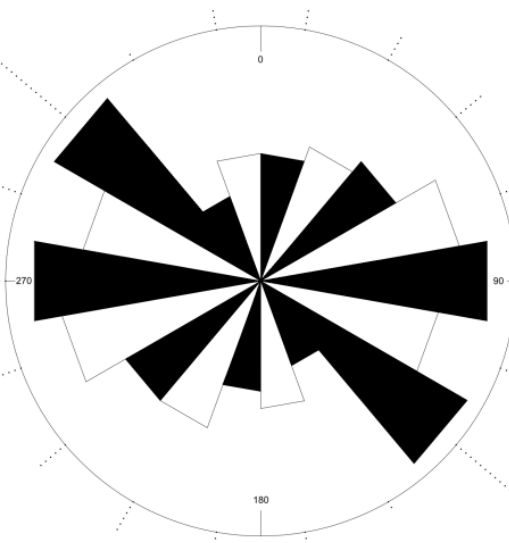




\section{Statistical analysis}

As noted earlier, the standard chi-square test, often used for determining significant preference for membership of a particular class from sets of contingency tables, is not really appropriate in its unmodified form for circular data. Figure 2 appears to indicate that the assemblage may be preferentially oriented WNW-ENE, but without a reliable independent assessment of the degree of variation from a non-preferential (random) orientated sample set it is difficult to be sure. Thus a statistical test of some kind is needed. If all angles are represented with the same degree of probability in the data set, then we may describe the pattern as uniform, and a statistical test for circular uniformity against a possible alternative is appropriate. If the alternative hypothesis to circular uniformity is a unimodal distribution (strongly preferential orientation in one direction), then the most powerful and commonly used test is the Rayleigh test. Where the alternative hypothesis is not a unimodal distribution (for example preferential orientation along two or more separate axes), then Bogdan et al (2000) argue that a more general, or "omnibus" test would be more appropriate, such as Kuiper's, Watson's, Anje's or Rao's tests (Bodgan et al 2000). In this dataset, a preferential orientation along one particular axis is expected, so, provided we can get around the difficulty that each orientation is potentially represented twice in the dataset, the Rayleigh test is clearly appropriate.

To do this, we see that the procedure used for plotting the rose diagram, (generating a second set of "mirrored" measurements, and adding them to the first) should be avoided in this case, as this artificially generates a polymodal distribution with twice the number of measurements actually recorded. Thus a different approach is required that will aggregate the measurements with their opposites on the compass circle without creating duplication, thus generating a unimodal distribution appropriate for the test. This can be accomplished with the following equation (after Berens 2009; see also Fisher 1993, p. 37), see also Table 2.

$\alpha \mathrm{i}=\rho \alpha \mathrm{i}(\bmod 2 \pi)$

Where $\alpha \mathrm{i}$ represents the new angle, and $\rho$ is the number of modes (in this case 2, for 2-dimensional axial data). Thus the measurements are first multiplied by 2 , and then adjusted (Modulo $2 \pi$ ) for the whole circle. Table 2 (below), shows this process for the first 5 bearing measurements. Note that as both modes give the same result; it is only ever necessary to calculate one mode. 
Table 2 (below), adjustment of axial data to a unimodal distribution (See Appendix I for complete data)

\begin{tabular}{|c|c|c|c|c|c|}
\hline \multicolumn{3}{|l|}{ mode 1} & \multicolumn{3}{|l|}{ mode 2} \\
\hline \multicolumn{2}{|c|}{ bearing radians } & $\alpha=\bmod \left(\alpha^{*} p, 2 p i\right)$ & \multirow{2}{*}{\begin{tabular}{|l} 
bearing \\
181
\end{tabular}} & \multicolumn{2}{|c|}{$\operatorname{radians} \alpha=\bmod \left(\alpha^{*} \mathbf{p}, 2 \mathbf{p i}\right)$} \\
\hline 1 & 0.017 & 0.035 & & 3.159 & 0.035 \\
\hline 1 & 0.017 & 0.035 & 181 & 3.159 & 0.035 \\
\hline 27 & 0.471 & 0.942 & 207 & 3.613 & 0.942 \\
\hline 31 & 0.541 & 1.082 & 211 & 3.683 & 1.082 \\
\hline 46 & 0.803 & 1.606 & 226 & 3.944 & 1.606 \\
\hline 47 & 0.820 & 1.641 & 227 & 3.962 & 1.641 \\
\hline
\end{tabular}

The Rayleigh test is applied by calculating the average bearing of the adjusted angles using a standard trigonometrical procedure for vectors of unknown magnitude known as Mardia's method or the unit vector average approach (Mori, 1987). The sum of all unit vectors is then used to derive a mean direction vector for the dataset, known as the mean resultant (r) by the Pythagorean equation. The step-by-step process is as follows:

First, each orientation measurement $(\theta)$ is treated as a unit vector $(v)$ with direction $\theta$ and magnitude $(m)=1$ and transformed into component form (i,j) by simply taking $\cos \theta(i)$ and $\sin \theta(j)$. All $i$ and all $j$ for each vector are then summed to produce $I$ and $J$ as shown in equations 2 and 3.

$I=\sum_{x=1}^{n} m\left(\cos \theta_{x}\right)$

$J=\sum_{x=1}^{n} m\left(\sin \theta_{x}\right)$

The mean resultant $(r)$ is then calculated as follows:

$r=\frac{\sqrt{I^{2}+J^{2}}}{n}$ 
Finally, the critical value for the test, or Z score, is computed by:

$\mathrm{Z}=\mathrm{nr}^{2}$

Where $\mathrm{n}$ is the number of observations and $\mathrm{r}$ is the mean resultant as calculated above. The $\mathrm{Z}$ value is then compared to a table of critical values for Rayleigh's z, such as that given by Zar (1999). For a step-by-step tutorial for the Rayleigh test, see Forrest (undated). In this case, the Rayleigh test was computed in excel and subsequently in $\mathrm{R}$, using the rayleigh.test routine contained in package circular. The test $\mathrm{Z}$ score of 6.342 allowed the null hypothesis (uniform orientation) to be rejected with a significance level ( $\mathrm{p}$-value) of $<0.002$ (in fact recorded by $\mathrm{R}$ as 0.0018 ).

Table 3: Results of the Rayleigh test for Southfleet rd elephant bone fragment orientations.

\begin{tabular}{|c|c|}
\hline Number of observations & 66 \\
\hline Sum of all i & 1.222 \\
\hline Sum of all $\mathbf{j}$ & -20.423 \\
\hline i squared & 1.493 \\
\hline j squared & 417.102 \\
\hline Mean resultant (r) by Eqn 4 & 0.310 \\
\hline \multicolumn{2}{|c|}{$\begin{array}{l}\text { The Rayleigh test: } \\
\text { to calculate the critical value }(Z) \text { for the test, we use } \\
Z=n{ }^{*} r \text { squared, where } n \text { is the number of observations and } r \text { is the mean resultant calculated } \\
\text { above }\end{array}$} \\
\hline $\mathbf{Z}$ & 6.342 \\
\hline \multicolumn{2}{|c|}{$\begin{array}{l}\text { Compared with tables in } \\
\text { Zar, J. H. 1999. Biostatistical Analysis, 4th ed. Prentice Hall, Upper Saddle River, NJ } \\
\text { gives a significant result at a probability of }<0.002\end{array}$} \\
\hline$R$ gives 0.0018 & \\
\hline
\end{tabular}

The Rayleigh test seems to indicate a non-uniform distribution, supporting the impression given by the rose diagram that the data are preferentially oriented WNW-ENE. To confirm these results, a second classic statistical test for circular data, the Kuiper test, was applied. In the Kuiper test, a variant of the Kolmogorov-Smirnov test adapted for periodic data, empirical data (the sample of 
long bone orientations), are compared against an ideal distribution representing uniform data. Since the test involves cumulative distribution functions, it is not easy to replicate in an excel spreadsheet, and the test was carried out in $\mathrm{R}$, using the kuiper.test routine contained in package circular with the same adjusted angular dataset as used for the Rayleigh test. According to Kuiper's test (Test Statistic: 2.4422), the null hypothesis (uniform orientation) can be rejected at a significance level of $<0.01$, less convincingly than with the Rayleigh test, but still much better than the $<0.05$ significance level commonly accepted in scientific literature. Within reasonable doubt, a preferential orientation for this data sample may be inferred.

\section{Conclusion}

This article has illustrated what we consider, on the basis of careful study of the technique and detailed examination of the relevant literature, to be "best practice" for preparing rose diagrams and applying statistical tests to orientation measurements from archaeological sites, be they mammal bone assemblages from Palaeolithic sites like the case study example, or alignments of monuments, architectural features or burials relating to the archaeology of later periods. In particular, three important lessons emerge from our study; 1) rose diagrams should be square-root scaled, as Wells (2000) has previously recommended, but which is still not always accounted for in software packages; 2) axial or "mirror image" orientation measurements need to be adjusted as shown in the article to produce a unimodal distribution suitable for analysis, and finally, 3) the popular chi-square test, so useful in many situations, is not recommended for orientation data since the results are very dependent on the choice of bins, which is usually arbitrary. While Wells (1990) has proposed a workaround, the simple Rayleigh test (which can be carried out in an excel spreadsheet) is a probably a better alternative as long as a single preferential orientation is expected. If there is a suggestion that multiple preferred orientations are possible, omnibus tests like Kuiper's (used here), Watson's, Anje's or Rao's tests are recommended.

\section{Acknowledgements}

The excavation work at the Southfleet Road elephant site was funded by Union Railways (North), subsequently High Speed 1. This support is gratefully acknowledged. 


\section{References}

Allen, P. P., Hewitt, R., Obryk, M. K., \& Doran, P. T. (2015). Sediment transport dynamics on an ice-covered lake: the 'floating'boulders of Lake Hoare, Antarctica. Antarctic Science, 27(2), 173184.

Ballantyne, C.K., and Cornish, R., (1979), Use of the chi-square test for the analysis of orientation data: Journal of Sedimentary Petrology, v. 49, p. 773-776.

Bertran, P., Texier, J.P., (1995). Fabric analysis: application to Paleolithic sites. J. Archaeol. Sci. 22, 521e535

Dale, M.L. \& Ballantyne, C.K., (1980). Two statistics for the analysis of orientation data in geography. The Professional Geographer, 32(2), pp.184-191.

Dibble, H.L., Chase, P.G., McPherron, S.P., Tuffreau, A., (1997.) Testing the reality of a "living floor" with archaeological data. Am. Antiq. 62, 629e651.

Dietze, M., \& Kleber, A. (2012). Contribution of lateral processes to stone pavement formation in deserts inferred from clast orientation patterns. Geomorphology, 139, 172-187.

Fisher, N.I., (1993), statistical analysis of circular data: Cambridge, UK, Cambridge University Press, $277 \mathrm{p}$

Forrest, T.G. undated, Circular Statistics: Analysis of Orientation and Time Data. Texas Tech University tutorial, http://www.rw.ttu.edu/4309/T-

ball\%20hab\%20select/Circular\%2520Statistics.pdf, accessed January 2012 Jammalamadaka, S. R., \& Sengupta, A. (2001). Topics in circular statistics (Vol. 5). World Scientific.

Kreuzer, L. (1987) Bone orientation data for the Clovis-age bed at the Lubbock Lake Landmark. Quaternary Research 29, p. 78-80

Krumbein, W. C. (1939). Preferred orientation of pebbles in sedimentary deposits. The Journal of Geology, 47(7), 673-706.Lund, U. and Agostinelli, C. (2018). Package CircStats. https://cran.rproject.org/web/packages/CircStats/CircStats.pdf

McPherron, S.J.P., (2005). Artifact orientations and site formation processes from total station proveniences. J. Archaeol. Sci. 32, $1003 \mathrm{e} 1014$.

Mori, Y, 1987, Methods for Estimating the Mean and the Standard Deviation of Wind Direction. Journal of Applied Meteorology, vol. 26, Issue 9, pp.1282-1284

Parfitt,S.A., Bello, S.M. Stewart, J.R.,Hewitt, R.J, Herridge, V.L., and Wenban-Smith, F.F. (2013)

Chapter 8. The elephant skeleton and the question of human exploitation. In Wenban-Smith, F.F. 
(ed). The Ebbsfleet Elephant: Excavations at Southfleet Road, Swanscombe in advance of High Speed 1, 2003 -4. Oxford Archaeology Monograph No. 20, Oxford.

Pearson, M. P. (1999). The archaeology of death and burial (p. 44). Phoenix Mill, UK: Sutton.R Core Team (2016). R: A language and environment for statistical computing. R Foundation for Statistical Computing, Vienna, Austria. URL https://www.R-project.org/.

R project (2012) circular package documentation, http://cran.r-

project.org/web/packages/circular/circular.pdf, accessed January 2012

Rigsby, G. P. (1960). Crystal orientation in glacier and in experimentally deformed ice. Journal of Glaciology, 3(27), 589-606.Roberts, M.B, Parfitt, S.A:, Pope, M.I., and Wenban-Smith, F.F., Macphail, R. I, Locker, A, and Stewart; J. R.(1997). Boxgrove, West Sussex : Rescue excavations of a lower Palaeolithic landsurface (Boxgrove project B, 1989-91), Proceedings of the Prehistoric Society, 63: 303-358. London.

Sahnouni, M., de Heinzelin, J.,(1998). The site of Ain Hanech revisited: new investigations at this Lower Pleistocene site in Northern Algeria. J. Archaeol. Sci. 25, 1083e1101.

Shipman, P. (1981), Life History of a Fossil; an introduction to Taphonomy and Paleoecology. Harvard University Press.

Shipman, P., \& Rose, J. (1983). Early hominid hunting, butchering, and carcass-processing behaviors: approaches to the fossil record. Journal of anthropological Archaeology, 2(1), 57-98. Voorhies, M. R. (1969). Taphonomy and population dynamics of an early Pliocene vertebrate fauna, Knox County, Nebraska (Vol. 1, pp. 1-69). Laramie: University of Wyoming. Wells, N. A., (1990). Comparing sets of circular orientations by modified chi-squared testing. Computers \& Geosciences, 16(8), pp.1155-1170.

Wells, N. A., (2000). Are there better alternatives to standard rose diagrams? Journal of Sedimentary Research, 70(1):37-46

Wenban-Smith, F.F. (ed.) (2013) The Ebbsfleet Elephant: Excavations at Southfleet Road, Swanscombe in advance of High Speed 1, 2003 -4. Oxford Archaeology Monograph No. 20, Oxford. 


\begin{tabular}{rrr} 
PI & $\begin{array}{l}\text { P (\# of } \\
\text { modes) }\end{array}$ & $\begin{array}{l}\text { n (\# of } \\
\text { observations) }\end{array}$ \\
\hline 3.141592654 & 2 & 66 \\
\hline
\end{tabular}

\begin{tabular}{|c|c|c|c|c|}
\hline \multirow{2}{*}{$\begin{array}{l}\text { Raw } \\
\text { orientation } \\
\text { data } \\
\text { (degrees) }\end{array}$} & \multirow[b]{2}{*}{ Radians } & \multirow{2}{*}{$\begin{array}{l}\text { Corrected for } \\
\text { axial data } \\
\text { (Eqn 1) }\end{array}$} & \multicolumn{2}{|c|}{$\begin{array}{l}\mathrm{i} \text { and } \mathrm{j} \\
\text { components }\end{array}$} \\
\hline & & & $\mathbf{i}$ & $\mathbf{j}$ \\
\hline 1 & 0.017 & 0.035 & 0.035 & 0.999 \\
\hline 1 & 0.017 & 0.035 & 0.035 & 0.999 \\
\hline 27 & 0.471 & 0.942 & 0.809 & 0.588 \\
\hline 31 & 0.541 & 1.082 & 0.883 & 0.469 \\
\hline 46 & 0.803 & 1.606 & 0.999 & -0.035 \\
\hline 47 & 0.820 & 1.641 & 0.998 & -0.070 \\
\hline 47 & 0.820 & 1.641 & 0.998 & -0.070 \\
\hline 48 & 0.838 & 1.676 & 0.995 & -0.105 \\
\hline 49 & 0.855 & 1.710 & 0.990 & -0.139 \\
\hline 49 & 0.855 & 1.710 & 0.990 & -0.139 \\
\hline 52 & 0.908 & 1.815 & 0.970 & -0.242 \\
\hline 52 & 0.908 & 1.815 & 0.970 & -0.242 \\
\hline 53 & 0.925 & 1.850 & 0.961 & -0.276 \\
\hline 53 & 0.925 & 1.850 & 0.961 & -0.276 \\
\hline 55 & 0.960 & 1.920 & 0.940 & -0.342 \\
\hline 65 & 1.134 & 2.269 & 0.766 & -0.643 \\
\hline 70 & 1.222 & 2.443 & 0.643 & -0.766 \\
\hline 71 & 1.239 & 2.478 & 0.616 & -0.788 \\
\hline 75 & 1.309 & 2.618 & 0.500 & -0.866 \\
\hline 77 & 1.344 & 2.688 & 0.438 & -0.899 \\
\hline 80 & 1.396 & 2.793 & 0.342 & -0.940 \\
\hline 84 & 1.466 & 2.932 & 0.208 & -0.978 \\
\hline 86 & 1.501 & 3.002 & 0.139 & -0.990 \\
\hline 88 & 1.536 & 3.072 & 0.070 & -0.998 \\
\hline 90 & 1.571 & 3.142 & 0.000 & -1.000 \\
\hline 93 & 1.623 & 3.246 & -0.105 & -0.995 \\
\hline 97 & 1.693 & 3.386 & -0.242 & -0.970 \\
\hline 99 & 1.728 & 3.456 & -0.309 & -0.951 \\
\hline 100 & 1.745 & 3.491 & -0.342 & -0.940 \\
\hline 105 & 1.833 & 3.665 & -0.500 & -0.866 \\
\hline 111 & 1.937 & 3.875 & -0.669 & -0.743 \\
\hline 113 & 1.972 & 3.944 & -0.719 & -0.695 \\
\hline 120 & 2.094 & 4.189 & -0.866 & -0.500 \\
\hline 121 & 2.112 & 4.224 & -0.883 & -0.469 \\
\hline 123 & 2.147 & 4.294 & -0.914 & -0.407 \\
\hline 124 & 2.164 & 4.328 & -0.927 & -0.375 \\
\hline 134 & 2.339 & 4.677 & -0.999 & -0.035 \\
\hline 137 & 2.391 & 4.782 & -0.998 & 0.070 \\
\hline 141 & 2.461 & 4.922 & -0.978 & 0.208 \\
\hline
\end{tabular}




\begin{tabular}{lllll}
144 & 2.513 & 5.027 & -0.951 & 0.309 \\
148 & 2.583 & 5.166 & -0.899 & 0.438 \\
155 & 2.705 & 5.411 & -0.766 & 0.643 \\
160 & 2.793 & 5.585 & -0.643 & 0.766 \\
165 & 2.880 & 5.760 & -0.500 & 0.866 \\
176 & 3.072 & 6.144 & -0.139 & 0.990 \\
193 & 3.368 & 0.454 & 0.438 & 0.899 \\
196 & 3.421 & 0.559 & 0.530 & 0.848 \\
233 & 4.067 & 1.850 & 0.961 & -0.276 \\
234 & 4.084 & 1.885 & 0.951 & -0.309 \\
235 & 4.102 & 1.920 & 0.940 & -0.342 \\
252 & 4.398 & 2.513 & 0.588 & -0.809 \\
260 & 4.538 & 2.793 & 0.342 & -0.940 \\
264 & 4.608 & 2.932 & 0.208 & -0.978 \\
266 & 4.643 & 3.002 & 0.139 & -0.990 \\
267 & 4.660 & 3.037 & 0.105 & -0.995 \\
272 & 4.747 & 3.211 & -0.070 & -0.998 \\
278 & 4.852 & 3.421 & -0.276 & -0.961 \\
287 & 5.009 & 3.735 & -0.559 & -0.829 \\
288 & 5.027 & 3.770 & -0.588 & -0.809 \\
294 & 5.131 & 3.979 & -0.743 & -0.669 \\
295 & 5.149 & 4.014 & -0.766 & -0.643 \\
295 & 5.149 & 4.014 & -0.766 & -0.643 \\
297 & 5.184 & 4.084 & -0.809 & -0.588 \\
311 & 5.428 & 4.573 & -0.990 & -0.139 \\
321 & 5.603 & 4.922 & -0.978 & 0.208 \\
350 & 6.109 & 5.934 & -0.342 & 0.940 \\
\hline & & & &
\end{tabular}




\title{
Appendix II, command-line output from $\mathbf{R}$ for rose diagrams and statistical tests
}

\author{
\#load required libraries \\ library(aspace) \#necessary for conversion to radians \\ library(CircStats) \#necessary for rose diagram plots \\ library(circular) \#necessary for statistical tests
}

\section{\#set working directory location}

setwd("E: \publications \longoing $\backslash \backslash J A S \backslash \backslash R ")$

\section{\#plot rose diagrams}

eleforient $<$ - read.table("eleflongorient.csv",sep=",", header=T)

$>$ head(eleforient,5)

orient

11

21

327

$4 \quad 31$

546

$>$ elefrad <- data.frame(lapply(eleforient,as_radians))

$>$ head(elefrad,5)

orient

10.01745329

20.01745329

30.47123890

40.54105207

50.80285146

rose.diag(elefrad, bins=18, main="Southfleet road elephant bone long axis orientations", prop=0.25, pts=TRUE, $\operatorname{cex}=0.5, \mathrm{pch}=16$, dotsep $=20$, shrink=1.3)

svg("rose_mirror_18bins.svg",width=20,height=20)

rose.diag(elefrad, bins $=18$, main="Southfleet road elephant bone long axis orientations", prop=0.25, 
$\mathrm{pts}=\mathrm{TRUE}, \operatorname{cex}=0.5, \mathrm{pch}=16$, dotsep $=20$, shrink $=1.3$ )

dev.off()

\section{\#statistical tests}

elefadj <- read.table("elefrad.csv",sep=",", header=T)

$>$ head(elefadj,5)

Corrected.for.axial.data

10.035

20.035

$3 \quad 0.942$

$4 \quad 1.082$

$5 \quad 1.606$

$>$ rayleigh.test(elefadj)

Rayleigh Test of Uniformity

General Unimodal Alternative

Test Statistic: 0.31

P-value: 0.0018

Warning message:

In as.circular(x) :

an object is coerced to the class 'circular' using default value for the following components:

type: 'angles'

units: 'radians'

template: 'none'

modulo: 'asis'

zero: 0

rotation: 'counter'

conversion.circularxradians0counter2pi 
$>$ kuiper.test(elefadj,alpha $=0$ )

Kuiper's Test of Uniformity

Test Statistic: 2.4432

$\mathrm{P}$-value $<0.01$

Warning message:

In as.circular( $\mathrm{x})$ :

an object is coerced to the class 'circular' using default value for the following components:

type: 'angles'

units: 'radians'

template: 'none'

modulo: 'asis'

zero: 0

rotation: 'counter'

conversion.circularxradians0counter2pi

\#save $R$ workspace and data, save command history

save.image("elefrose.RData")

savehistory() 